\author{
Vol. 1, No.1,1993
}

\title{
MICELLAR CATALYZED HYDROLYSIS OF A PHOSPHATE ESTER IN AQUEOUS SOLUTIONS CONTAINING DIMETHYL SULFOXIDE
}

\author{
Lavinel G. Ionescu* and Elizabeth Fátima de Souza \\ Instituto de Quimica \\ Pontifícia Universidade Católica do Rio Grande do Sul \\ Porto Alegre, RS BRASTL 90610-001 \\ \& \\ Departamento de Química \\ Universidade luterana do Brasil \\ Canoas, RS BRASIL $92420-280$
}

\begin{abstract}
The hydrotysis of p-nitrophenyldiphenyl phosphate was studied in aqueous solutions containing micelles of diethylheptadecylimidazolinim ethyl sulfate (DEHIES), sodium hydroxide and various concentrations of dimethyl sulfoxide (DMSO). Pseudo-first order $\left(k_{\psi}\right)$ and second order rate constants $\left(k_{2}\right)$ were determined at 250, $25 \%$ and $35 \% C$ and activation parcometers such as $E_{a,}, \triangle G$, $\triangle H^{\prime}$ and $\Delta S^{\prime}$ were also measured. The rate profiles obtained for solutions containing 20-50\% DMSO by volume exhibited clear maxima that shifted to higher concentrations of DEHIES as a function of DMSO added. For solutions containing 60-80\% DMSO there was no maximum in the rate profite and inhibition of the reaction took place. Solutions containing $90 \%$ by volume of DMSO exhibited much higher reaction rates and considerably more catalysis. The experimental results are explained in terms of the Hughes-Ingold Theory, specific solvent effects, polarity and internal pressure of the reaction medium. The interpretation and discussion of the results takes into consideration the formation of the stoichiometric hydrate DMSO.2H:O and the inhibitory effect of dimethyl sulfoxide on the formation of micelles of DEHIES.
\end{abstract}

\section{RESUMO}

A hidrólise do p-nitrofenildifenilfosfato foi estudada em solucões contendo micelas de dietilheptadecil-etilsulfato-imidazolinio (DEHIES), hidróxido de sódio e vámias concentrasões de dimetilsulföxido (DMSO). Foram determinadas constantes de velocidade de pseudo-primeira ordem ( $k x$ )' segunda ordem $\left(k_{2}\right)$ e parômetros de ativação tais como $E_{a} . \Delta G^{\neq}, \Delta H^{\neq}$e $\Delta S^{\neq}$. Para soluçóes contendo $20-50 \%$ de DMSO por volume os perfis de velocidade apresentam um maximo bem definido, destocado para concentraçóes mais elevadas de DEHIES em função de DMSO adicionado. Para solusốes com 60-80\% DMSO não ha um maximo no perfil de velocidades e ocorre uma inibicão da reasão. para solucões contendo $90 \%$ por volume de DMSO, as velocidades de reacão são consideravelmente mais elevadas com catälise mito pronunciada. us resultados experimentais são explicados em termos da Teoria Hughes-Ingold, dos efeitos especificos do solvente, da polaridade e da pressão interma do meio de reasão. $A$ discussão e interpretą̧̃o dos resultados leva em consideração a formąão do hidrato estequiométrico DMSO. $2 \mathrm{H}_{2} \mathrm{O}$ e o efeito inibitório do DMSO sobre a formasão de micelas de DEHIES.

KEYWORDS: Micellar Catalysis, Dimethyl Sulfoxide, Internal Pressure, Solvente Effects, Mixed Solvent Systems, Phosphate Esters

* Author to whom correspondence should be addressed.

$\S$ PPGEMM-UFRGS 


\section{INTRODUCTION}

Phosphate esters represent a group of compounds with interesting biochemical and pharmacological properties and have a wide use as pesticides, drugs and nerve gases. 1,2

In previous studies we have shown that the hydrolysis of $d i$ - and $t r i-s u b s t i t u t e d$ phosphate esters is catalyzed by micelles of cetyltrimethylammonium bromide (CTAB) and also by micelles of $\mathrm{N}, \mathrm{N}$-dimethyl-N-hydroxyethyldodecylammoni um bromide (DHEDAB) and $\mathrm{N}, \mathrm{N}$-dimethyl-N-hydroxyethylcetylammonium bromide (CHEDAB). 3 Micelles of DHEDAB and CHEDAB are excellent catalysts for the hydrolysis of both lithium p-nitrophenyl. ethyl phosphate (LiPNEF) and $p$-nitrophenyldipnehyl phosphate (PNFDF) in the presence of $\mathrm{OH}^{-}$, with over a 300-fold rate enhancement for the hydrolysis of the triaryl phosphate in the presence of CHEDAB. The catalytic effect and the dependence of the reaction rate on hydroxide-ion concentration has been explained in terms of nucleophilic participation of the alkoxide ions of DHEDAB and CHEDAB, with values of $\mathrm{pK}_{a}$ of 12,4 and 12,9 , respectively for the ionization of the hydroxyl group. For reactions with fluoride ion, the hydroxy-substituted surfactants (functional micelles) are no better catalysts than the corresponding alkyltrimethyl ammonium bromides, suggesting that electrophilic catalysis is relatively unimportant. Cetylpyridinium bromide (CPBr) has approximately the same effect as CTAB at low hydroxide concentration and a slightly more pronounced effect with fluoride ion. Zwitterionic surfactants such as lauryl carnitine chloride (LCCI) and palmityl carnitine chloride (PCC1) 4,5 have little effect on the rate of hydrolysis of LiPNEF.

The addition of primary amines increased the rate of reaction in the presence of CTAB and CHEDAB for the triaryl phosphate, but much of the increase was due to attack by amine on the aryl group. In the absence of micells, amines increased the overall rate of the reaction by attacking the aryl group without markedly catalyzing hydrolysis. 6

The study of the micellar catalyzed dehydrochlorination of $1,1,1-t$ richloro-2,2-bis ( - -chloropheny 1$)$ ethane (DDT) and some of its derivatives, as well as the hydrolysis of lithium p-nitrophenyl ethyl phosphate (LiPNEF) in the presence of higher concentrations of hydroxide ion $(0,10$ to $5,0 \mathrm{M})$ in the presence and absence of salts, showed that the pseudo-phase ion exchange model fails and does not explain experimental results. In fact, some systems contain liquid crystalline mesophases and a mode $1-15$

The present paper deals with the study of the hydrolysis of p-nitrophenyl diphenyl phosphate in aqueous solutions containing sodium hydroxide, micelles of diethylheptadecylimidazolinium ethyl sulfate (DEHIES) and dimethyl sulfoxide (DMSO). The reaction under consideration is illustrated below.

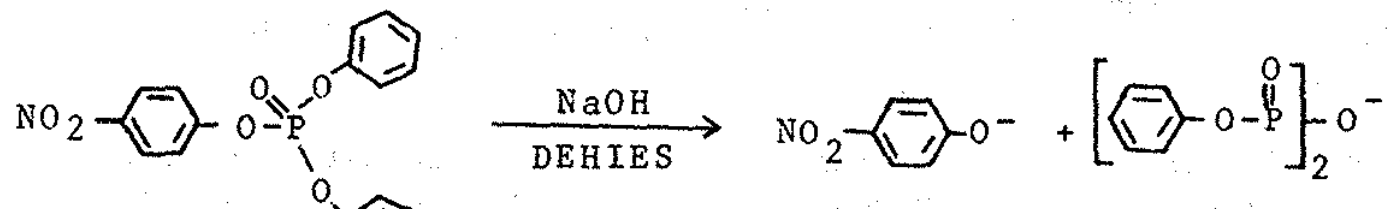




\section{EXPRRIMENTAL PROCEDURE}

MATERIALS. The phosphate ester, p-nitrophenyl diphenyl phosphate (PNFDF) was prepared by standard methods 16-19. A sample was also obtained from Prof. Fred M. Menger, Emory University, Atlanta, Georgia, USA. The surfactant, diethylheptadecylimidazolinium ethyl sulfate (DEHIES) was obtained from Chem Service Inc., West Chester, Pennsylvania, USA. Dimethyl sulfoxide (DMSO) and sodium hydroxide were analytical reagent grade and were purchased from Merck do Brasil, Rio de Janeiro. They were used without further purification.

MICELLE FORMATION. The critical micellar concentration (CMC) of the surfactant DEHIES was determined at $25 \%, 32 \%$ and $409 \mathrm{C}$ by measurement of the surface tension of DEHIES-H 20 -DMSO solutions using a Fisher Model 21 Semi-Automatic Tensiometer. The thermodynamic parameters for micellization including the free energy, $\triangle G$, enthalpy, $\triangle H_{\mathrm{m}}$ and the entropy. of micelizization, $\triangle \mathrm{S}_{\mathrm{m}}$, were calculated from CMC data using standard equations. $20-22$

KINETICS. The hydrolysis of $p$-nitrophenyl diphenyl phosphate (PNFDF) was studied spectrophotometrically meaguring the rate of appearance of the $p$-nitrophenoxide ion at $4030 \AA$. A Varian DMS-80 spectrophotometer equipped with a water-jacketted cell compartment was used. The reaction was studied at $15 \%, 259$ and $359 \mathrm{C}$ at various concentrations of $\mathrm{NaOH}$, DMSO and DEHIES. The pseudo-first order rate constant, $k \psi$, in sec-1 was determined from linear plots of $\ln \left(A_{\infty}-A_{t}\right)$ versus time. The second order rate constants $\left(k_{2}\right)$ were calculated from kw and the hydroxide ion concentration. Activation parameters such as $E_{a}, \Delta H^{\neq}, \Delta G^{\neq}$and $\Delta S \neq$ were also determined using the following equations.

$$
\begin{aligned}
& \ln k \psi=\ln A-\left(E_{a} / R\right)(1 / T) \\
& \Delta H^{\neq}=E_{a}-R T \\
& \Delta S^{\neq}=4,576\left(\operatorname{Rog} k \psi^{*}-10,753-\log \mathrm{T}+E_{a} / 4,576 \mathrm{~T}\right) \\
& \Delta G^{\neq}=\Delta H^{\neq}-\mathrm{T} \Delta \mathrm{S}^{\neq}
\end{aligned}
$$

\section{RESULTS AND DISCUSSION}

Some representative results obtained for the critical micellar concentration (CMC) of DEHIES at $25 \%$ and $409 \mathrm{C}$ are illustrated in Table $I$. The CMC values were obtained from the inflection point of plots of surface tension versus concentration or logarithm ( $\log _{10}$ ) of the concentration for fixed amounts of DMSO. As can be seen, the critical micellar concentration of the surfactant increases both as a function of temperature and DMSO added. The addition of DMSO 
hinders the formation of micelles in the DEHIES-H 20 -DMSO ternary system.

TABLE I. CRITICAL MICELLAR CONCENTRATION OF DIETHYLHEPTADECYLIMIDAZOLINIUM ETHYL SULFATE IN AQUEOUS SOLUTIONS CONTAINING DIMETYL SULFOXIDE AT $250^{\circ}$ AND $400^{\circ} \mathrm{C}$.

\begin{tabular}{cccc}
$\begin{array}{c}\text { Percent DMSO } \\
(\text { by volume })\end{array}$ & $\begin{array}{c}\text { Mole Fraction } \\
\left(\mathrm{X}_{\text {DMSO }}\right)\end{array}$ & $\begin{array}{c}\text { CMC at 259C } \\
\left(\mathrm{M} \times 10^{3}\right)\end{array}$ & $\begin{array}{c}\text { CMC at } 409 \mathrm{C} \\
\left(\mathrm{M} \times 10^{3}\right)\end{array}$ \\
\hline 0 & 0,000 & 0,25 & 0,28 \\
10 & 0,028 & 0,40 & 0,45 \\
20 & 0,060 & 0,44 & 0,50 \\
30 & 0,099 & 0,55 & 0,66 \\
40 & 0,145 & 1,10 & 1,32 \\
50 & 0,203 & 2,75 & 3,47 \\
60 & 0,277 & 5,13 & 6,61
\end{tabular}

TABLE II, THERMODYNAMIC PARAMETERS FOR THE FORMATION OF MICELLES OF DIETHYLHEPTADECYLIMIDAZOLINIUM ETHYL SULFATE IN AQUEOUS SOLUTIONS OF DIMETHYL SULFOXIDE AT 25 OC.

\begin{tabular}{ccccc}
$\begin{array}{c}\text { Percent DMSo } \\
(\text { by volume })\end{array}$ & $\begin{array}{c}\text { Mole Fraction } \\
\left(\mathrm{X}_{\text {DMSO }}\right)\end{array}$ & $\begin{array}{c}\Delta \mathrm{G}^{\circ}{ }_{\mathrm{m}} \\
(\mathrm{kcal} / \mathrm{mol})\end{array}$ & $\begin{array}{c}\Delta \mathrm{H}^{\circ} \mathrm{m} \\
(\mathrm{kcal} / \mathrm{mol})\end{array}$ & $\begin{array}{c}\Delta \mathrm{S}_{\mathrm{m}}^{\circ} \\
\mathrm{eu})\end{array}$ \\
\hline 0 & 0,000 & $-4,91$ & $-1,41$ & $+11,8$ \\
10 & 0,028 & $-4,64$ & $-1,47$ & $+10,6$ \\
20 & 0,060 & $-4,58$ & $-1,59$ & $+10,0$ \\
30 & 0,099 & $-4,45$ & $-2,27$ & $+7,3$ \\
40 & 0,145 & $-4,04$ & $-2,26$ & $+6,0$ \\
50 & 0,203 & $-3,49$ & $-2,28$ & $+2,1$ \\
60 & 0,277 & $-3,12$ & $-3,15$ & $+0,1$ \\
\hline
\end{tabular}


Table II summarizes the thermodynamic parameters obtained for the micellization of DEHIES in aqueous solutions of DMSO at $25 \% \mathrm{C}$. The standard free energy of micellization, $\triangle \mathrm{Go}$, varies almost 1 inearly from $-4,64 \mathrm{kcal} / \mathrm{mole}$ to $-3,12 \mathrm{kcal} / \mathrm{mole}$ with increasing concentration of DMSO. The value of $\triangle G_{\dot{m}}^{\circ}$ determined for DEHIES alone in pure water was $-4,91 \mathrm{kcal} / \mathrm{mole}$, indicating that the micellization process is more spontaneous in pure water. The enthalpy of micellization, $\triangle H^{\circ}$, calculated experimentally is exothermic and similar to watem for low concentrations of DMSO $(-1,41$ to $-1,59 \mathrm{kcal} / \mathrm{mole})$. For higher concentrations it becomes more pronounced (more exothermic), indicating stronger interactions between $\mathrm{H}_{2} \mathrm{O}$ and DMSO. $\triangle \mathrm{S} \stackrel{\mathrm{m}}{\mathrm{m}}$ decreases gradually from $+11,8$ to $+0,1$ eu.

Similar results have been reported for the cetyltrimethylammonium - water-dimethyl sulfoxide system (CTAB-H O-DMSO) and have been explained in terms of the formation of the DMSO. $2 \mathrm{H}_{2} \mathrm{O}$ stoichiometric hydrate. 24-26 As can be seen in Table II from the $\triangle S O$ values, an increase in orderliness of the DEHIES-H $20-D M S O$ system takes place as the mole fraction of DMSO is increased. In fact, results of proton spin-lattice relaxation studies have shown that the increased structuring of the DMSO- ${ }_{2} \mathrm{O}$ liquid system resulting in the formation of the stoichiometric hydrate DMSO. $2 \mathrm{H}_{2} \mathrm{O}$ overcomes the hydrophobic effect of the alkyl chain of CTAB and inhibits totally the formation of micelles at a mole fraction of DMSO ( $\mathrm{X}_{\mathrm{DMSO}}$ ) of about 0,33 in accordance with results obtained by surface tensiometry. Under these conditions plots of surface tension for $\mathrm{CTAB}-\mathrm{H}_{2} \mathrm{O}-\mathrm{DMSO}$ versus concentration of CTAB are linear. Proton spin-lattice relaxation times $\left(1 / T_{1}\right)$ and average rotational correlation times, $\tau s(R)$, for the terminal methyl, $\mathrm{N}$-methyl and methylene groups of CTAB as well as effective activation energies obtained for the various relaxation processes in water-dimethyl sulfoxide solutions showed that the surfactant molecules become trapped in the crystalline lattice of the DMSO. $2 \mathrm{H}_{2} \mathrm{O}$ hydrate. $25-27$

Some typical experimental results obtained for the pseudofirst order rate constant $k \psi$ for the hydrolysis of $p$-nitrophenyl diphenyl phosphate (PNFDF) at 25 OC as a function of DEHIES and various fixed amounts of $\mathrm{NaOH}$ are shown in Figure 1 . The rate profiles are representative of micellar catalyzed reactions. The addition of surfactant to the reaction medium causes an increase in the rate of hydrolysis up to a point where there is complete incorporation of the substrate in the micellar phase. Further increase in the concentration of surfactant causes a decrease in the rate of reaction, probably due to dilution of the reactive counterions in the stern layer. There is a maximum in all rate profiles at about $15 \times 10^{-4} \mathrm{M}$ DEHIES as compared to $20 \times 10^{-4} \mathrm{M}$ for CTAB. All curves also show a secondary maximum at about $8 \times 10^{-4}$ M DEHIES that is probaly due to the formation of premicellar aggregates. For aqueous solutions containing $0,020 \mathrm{M} \mathrm{NaOH}$ the catalytic effect (ratio of the rate in the presence and absence of surfactant under the same conditions) is about 40-fold for DEHIES as compared to 80 -fold for CTAB. The difference is 


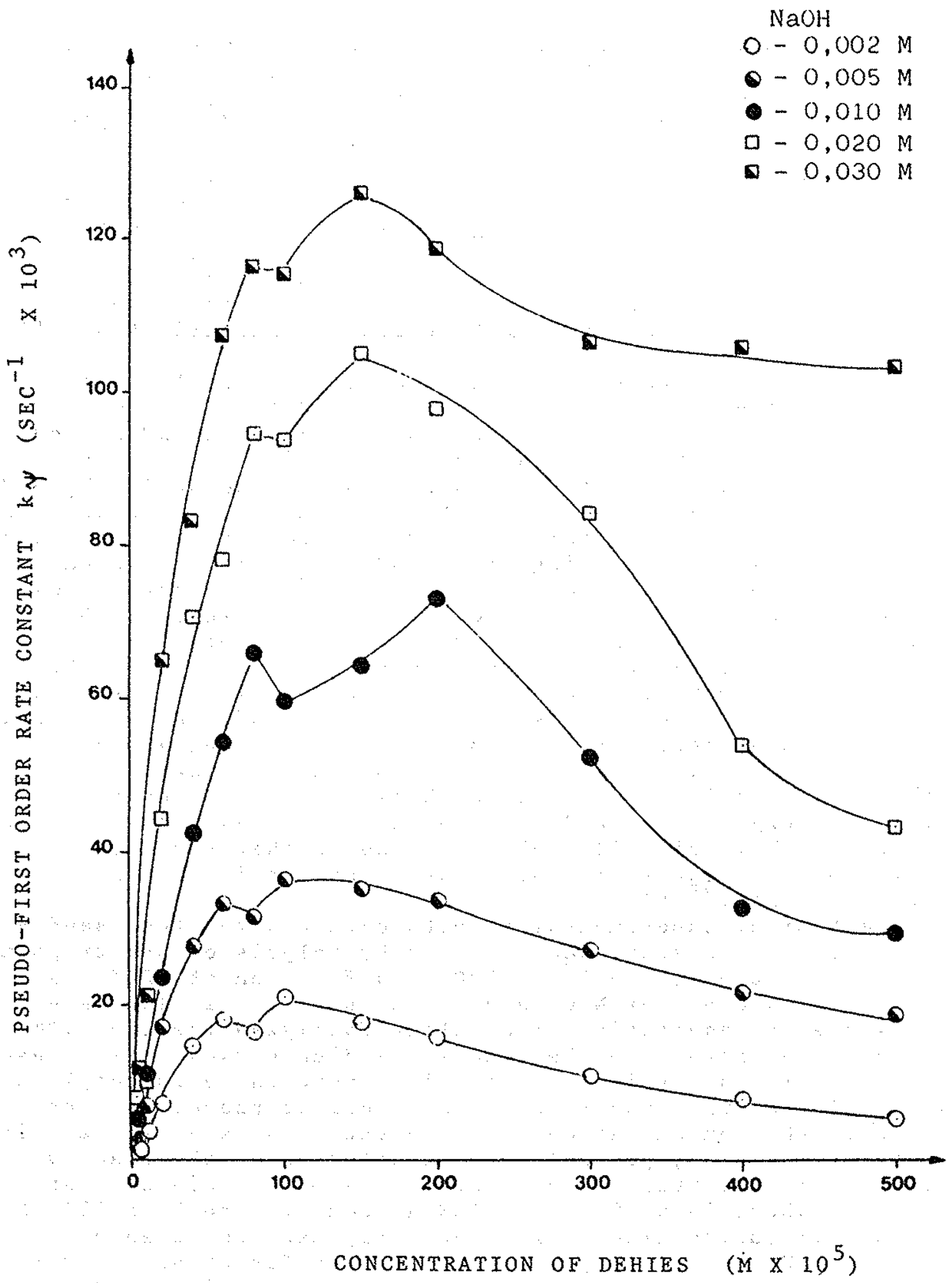

FIGURE 1. RATE PROFILES FOR THE HYDROLYSIS OF $p$-NITROPHENYL DIPHENYL PHOSPHATE AT 25\%C IN AQUEOUS SOLUTIONS CONTAINING SODIUM HYDROXIDE AND MICELLES OF DIETHYLHEPTADECYLIMIDAZOLINIUM ETHYL SULFATE (DEHIES). 
attributed to the large difference in the head group of the two surfactants. Second order rate constants for the reaction (k $\left.{ }_{2}\right)$ have an average value of $6,0 \mathrm{sec}^{-1}$ mole -1 and the reaction can be essentially considered as second order in hydroxide ion.

Figure 2 illustrates typical rate profiles obtained for the hydrolysis of PNFDF in aqueous solutions containing $0,010 \mathrm{M}$ $\mathrm{NaOH}$ and different concentrations of surfactant and dimethyl sulfoxide at $25 \% \mathrm{C}$. For a fixed concentration of $30 \%$ DMSO by volume there is a similar behavior to that observed for the aqueous solutions without DMSO, with a maximum in the rate profile shifted to higher concentrations of surfactant. For solutions with $60 \%$ DMSO by volume there is a relative inhibition of the reaction, but the reaction rates are slightly higher than for the corresponding DMSO-H ${ }_{2} \mathrm{O}$ solutions without surfactant. There is no clear maximum in the rate profile. For solutions containing $90 \%$ DMSO by volume the reaction rates measured are considerably higher than under other conditions studied. An inhibition of the reaction takes place at concentrations above $20 \times 10^{-4} \mathrm{M}$ DEHIES.

Figure 3 shows the variation of the pseudo-first order rate constant at $25 \% \mathrm{C}$ for the reaction under consideration in the absence of surfactant : at a fixed concentration of $\mathrm{NaOH}(0,010 \mathrm{M})$ and varying mole fraction of DMSO.

Figure 4 illustrates the dependence of the pseudo-first order rate constant ( $k \psi$ ) on the mole fraction of DMSO for fixed concentrations of $\mathrm{NaOH}(0,010 \mathrm{M})$ and surfactant $\left(15 \times 10^{-4} \mathrm{M}\right.$ DEHIES).

Figure 5 shows on the same scale the results mentioned above and compares them to those obtained for aqueous solutions containing a fixed concentration of cetyltrimethyl ammonium bromide $\left(\mathrm{CTAB}=20 \times 10^{-4} \mathrm{M}\right)$, at the maxima in the rate profiles.

It can be clearly noted that low concentrations of DMSO have a pronounced effect on the reaction rates in the presence of the two surfactants. At mole fractions of DMSO above 0,2 the rate constants for the three systems $\mathrm{H}_{2} \mathrm{O}-\mathrm{DMSO}, \mathrm{H}_{2} \mathrm{O}-\mathrm{DMSO}-\mathrm{CTAB}$ and $\mathrm{H}_{2} \mathrm{O}-\mathrm{DMSO}-\mathrm{DEH} \mathrm{IES}$ become much less sensitive to the addition of the cosolvent.

A more detailed analysis of Figure 5 shows three different types of behavior of the rate constant as a function of the mole fraction of the cosolvent. In the Diso mole fraction range where micelle formation takes place (10-60\% by volume), an increase in the amount of cosolvent decreases the rate of the reaction. At about $70 \%$ by volume of DMSO the rate constant attains minimum values and at concentrations of DMSO above $80 \%$ by volume the reaction rates increase considerably.

The three different behaviors of the rate constants (that are essentially similar for CTAB and DEHIES) are explained in terms of the effect of DMSO on micelle formation. At low concentrations of DMSO where micelles exist, but the micellization process is inhibited by DMSO, the addition of the cosolvent decreases the rate constant of the reaction. At higher concentrations of DMSO, where there are no micelles, the system is essentially controlled by the influence of the dipolar aprotic solvent that also acts as a catalyst for the reaction. In the intermediate region $(60-70 \%$ by volume of cosolvent), where the stoichiometric hydrate DMSO $2 \mathrm{H}_{2} \mathrm{O}$ forms, the behavior is similar to the solution without 


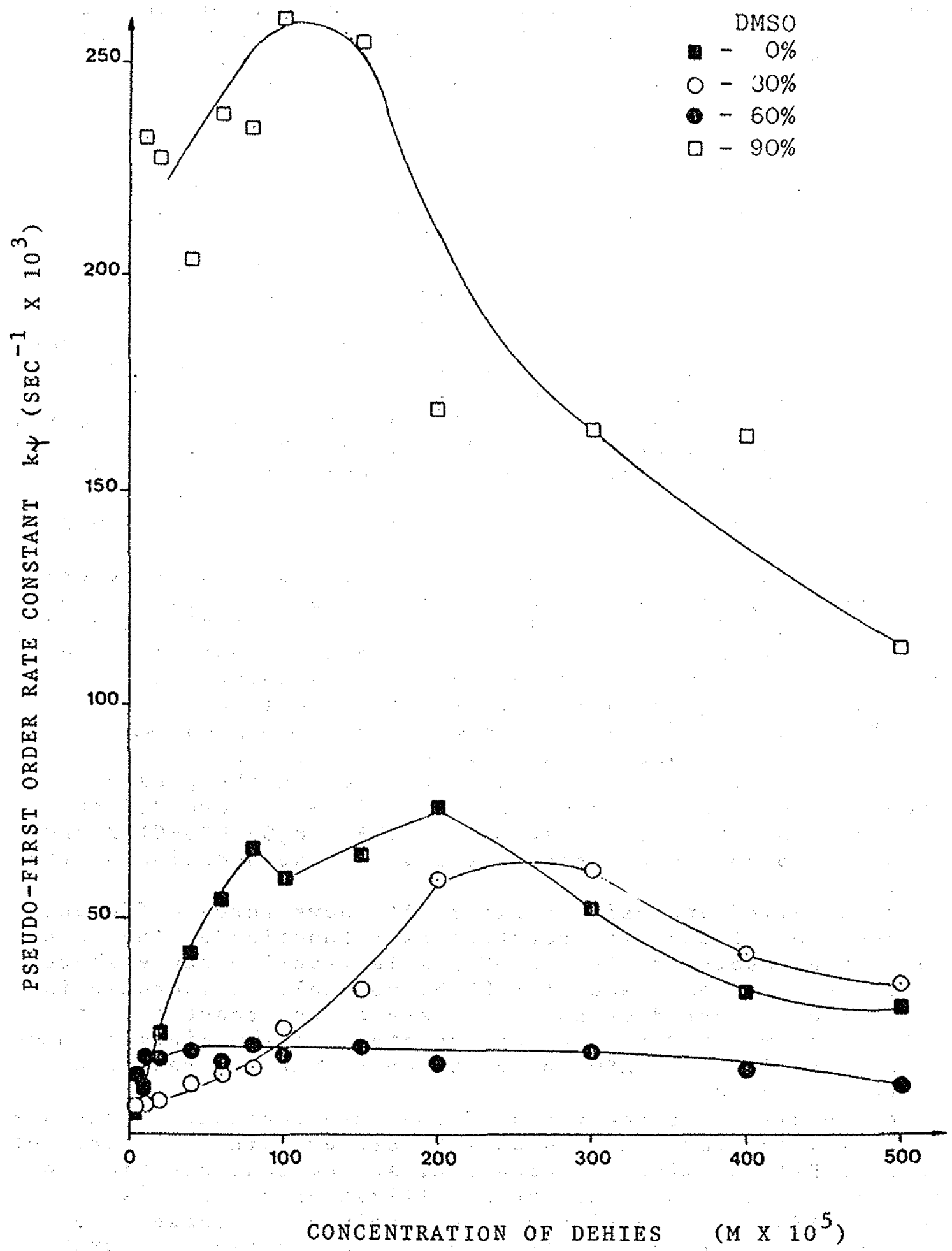

FIGURE 2. RATE PROFILES FOR THE HYDROLYSIS OF $p$-NITROPHENYL DIPHENYL PHOSPHATE AT 25:C IN AQUEOUS SOLUTIONS CONTAINING 0,010 M SODIUM HYDROXIDE TN THE PRESENCE OF DEHIES AND VARIOUS CONCENTRATIONS OF DMSO. 


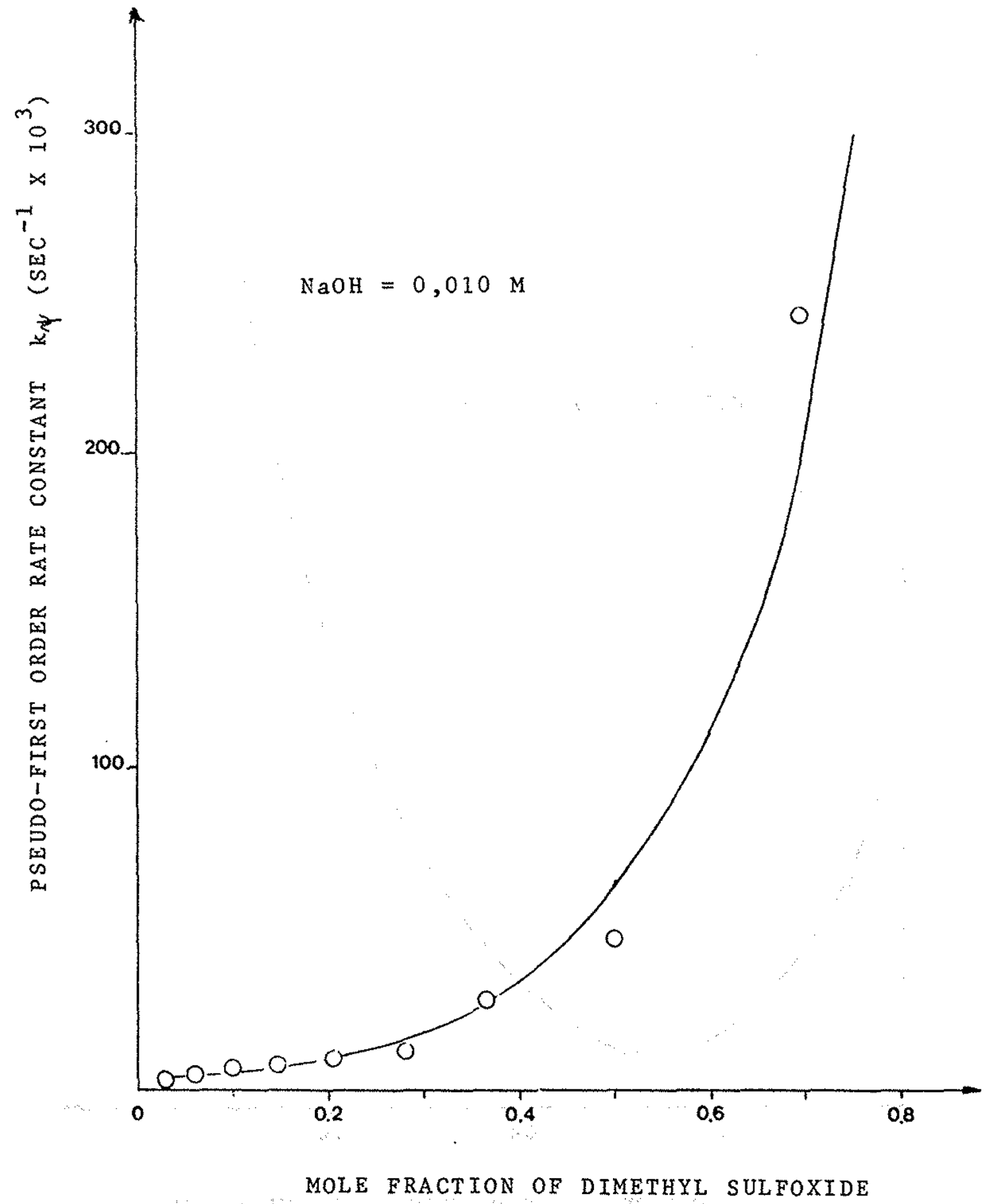

FIGURE 3. PLOT OF THE PSEUDO-FIRST ORDER RATE CONSTANT FOR THE HYDROLYSIS OF $p$-NITROPHENYL DIPHENYL PHOSPHATE AT $25 \% \mathrm{C}$ AS A FUNCTION OF THE MOLE FRACTION OF DMSO. 


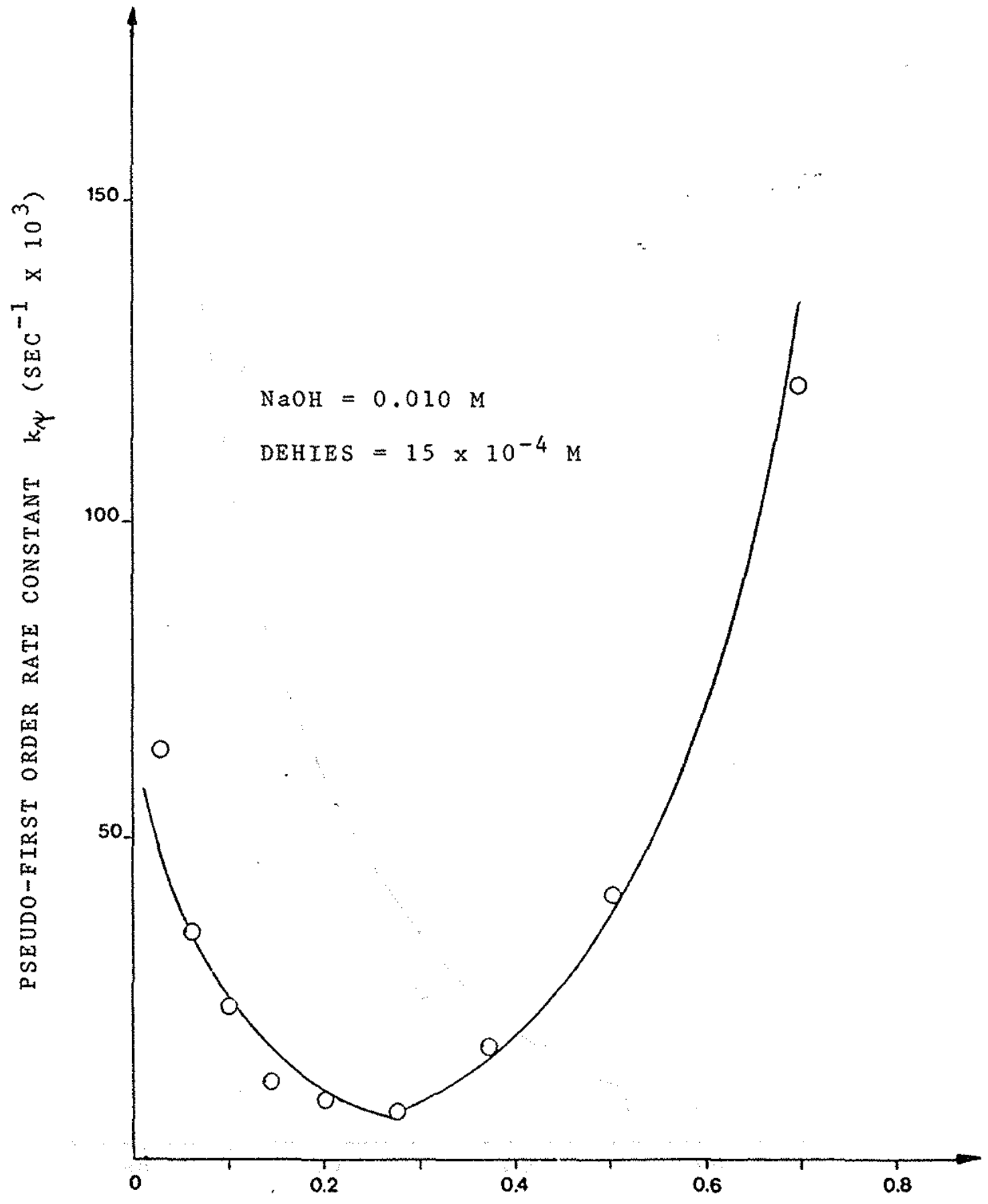

MOLE FRACTION OF DIMETHYL SULFOXIDE

FIGURE 4. PLOT OF THE PSEUDO-FIRST ORDER RATE CONSTANT FOR THE HYDROLYSIS OF $p$-NITROPHENYL DIPHENYL PHOSPHATE AS A FUNCTION OF THE MOLE FRACTION OF DMSO FOR AQUEOUS SOLUTIONS CONTAINING $0,010 \mathrm{M}$ SODIUM HYDROXIDE AND $15 \times 10^{-4} \mathrm{M}$ DEHIES AT 25 \% C. 


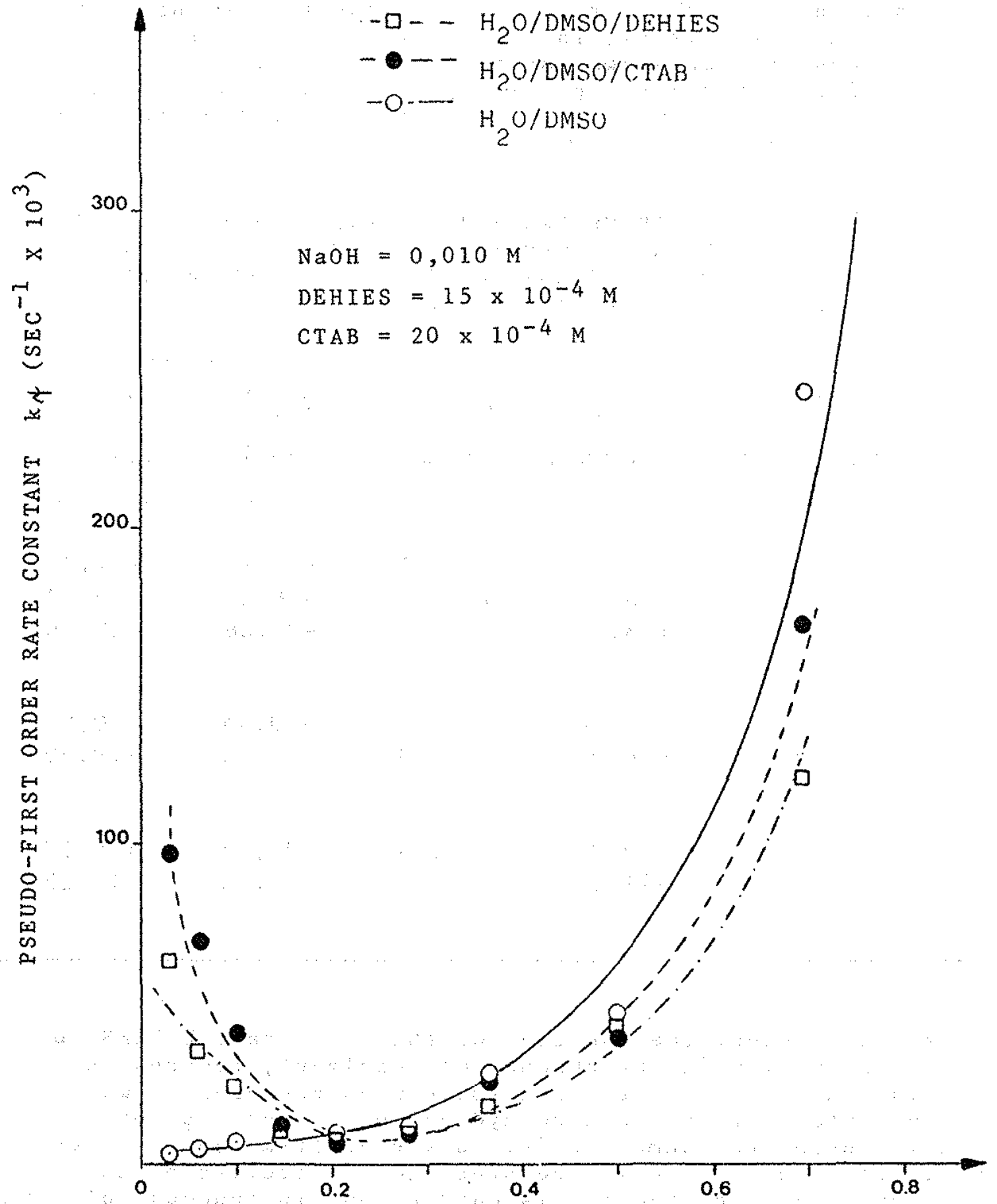

MOLE FRACTION OF DIMETHYL SULFOXIDE

FIGURE 5. PLOT OF THE PSEUDO-FIRST ORDER RATE FOR THE HYDROLYSIS OF $p$-NITROPHENYL DIPHENYL PHOSPHATE AT 25OC AS A FUNCTION OF THE MOLE FRACTION OF DMSO FOR FIXED CONCENTRATIONS OF NaOH, CTAB AND DEHIES. 
surfactant. In fact, the surfactant is present in solution as dispersed monomers, trapped in the crystal lattice of the DMSO $2 \mathrm{H}_{2} \mathrm{O}$ hydrate, as shown for the case of CTAB. 25-27

Table III summarizes typical experimental results obtained for the activation parameters of the reaction in the presence and absence of DEHIES at $25 \circ \mathrm{C}$.

TABLE III. ACTIVATION PARAMETERS FOR THE HYDROLYSIS OF $p$-NITROPHENYL DIPHENYL PHOSPHATE IN AQUEOUS SOLUTIONS OF 0,010 M SODIUM HYDROXIDE AT 25OC IN THE PRESENCE AND ABSENCE OF DEHIES AND DMSO.

\begin{tabular}{|c|c|c|c|c|c|}
\hline \multicolumn{2}{|c|}{ Concentration } & \multirow{2}{*}{$\begin{array}{c}\mathrm{Ea} \\
(\mathrm{kcal} / \mathrm{mol})\end{array}$} & \multirow{2}{*}{$\begin{array}{c}\Delta \mathrm{H}^{\circ} \neq \\
(\mathrm{kcal} / \mathrm{mol})\end{array}$} & \multirow{2}{*}{$\begin{array}{c}\Delta S^{\circ} \neq \\
(\mathrm{eu})\end{array}$} & \multirow{2}{*}{$\begin{array}{c}\Delta \mathrm{G}^{\circ} \neq \\
(\mathrm{kcal} / \mathrm{mol})\end{array}$} \\
\hline $\begin{array}{l}\text { DMSO } \\
\text { (\% vol.) }\end{array}$ & $\begin{array}{l}\text { DEHIES } \\
\left(M \times 10^{3}\right)\end{array}$ & & & & \\
\hline - & - & $+15,23$ & $+14,64$ & $-22,24$ & $+21,27$ \\
\hline- & 100 & $+8,82$ & $+8,22$ & $-36,60$ & $+19,14$ \\
\hline- & 150 & $+8,61$ & $+8,02$ & $-37,08$ & $+19,08$ \\
\hline 10 & - & $+18,74$ & $+18,15$ & $-9,44$ & $+20,96$ \\
\hline 10 & 100 & $+14,68$ & $+14,08$ & $-17,46$ & $+19,29$ \\
\hline 90 & - & $+9,03$ & $+8,14$ & $-32,64$ & $+18,17$ \\
\hline 90 & 100 & $+11,29$ & $+10,70$ & $-25,26$ & $+18,23$ \\
\hline
\end{tabular}

As can be seen, the addition of the surfactant DEHIES to the reaction medium in the absence of cosolvent, reduces the activation energy, $\mathrm{E}_{\mathrm{a}}$, about $7 \mathrm{kcal} / \mathrm{mole}$ when compared to water solution containing only sodium hydroxide. The entropy of activation under the same conditions varies from about -22 eu in water to about -37 eu in the presence of micelles of the surfactant. When the reaction is carried out in aqueous solutions containing $10 \%$ DMSO by volume, the addition of surfactant decreases the energy of activation about $4 \mathrm{kcal} / \mathrm{mole}$ and reduces the entropy of activation from -9 eu to -17 eu. For the case of solutions containing $90 \%$ DMSO by volume, the addition of surfactant increases the activation energy about $2 \mathrm{kcal} / \mathrm{mole}$ and increases the entropy of activation from about -32 eu to -25 eu. In summary, the addition of surfactant to pure water solutions 
or to water solutions containing $10 \%$ DMSO by volume 1 eads to a more structured transition state (due to the presence of micelles) and facilitates the occurrence of the reaction.

For solutions containing $90 \%$ by volume DMSO, that already represents a highly structured medium, the addition of the surfactant, that is now present as dispersed non-aggregated monomers, causes a destructuring of the transition state and an inhibition of the reaction. Analysis of the variation of $\triangle G^{\neq}$, $\triangle H \neq$ and $\triangle S^{\neq}$as a function of solvent shows that this reaction follows the isokinetic or compensation law and permits us to suggest that the presence of micelles in the reaction medium does not alter the mechanism of the reaction. 28

Interactions in liquid solutions and the effect of solvents on the rate of bimolecular reactions are rather complex subjects and have been treated extensively in the literature. $29-38$

one approach uses the transition state theory and considers the relative solvation between the initial and transition state. The solvation of any of these states reduces the free energy and increases the stability. For a solvent to increase the rate of reaction it is necessary to reduce the activation free energy $\left(\triangle G^{\neq}\right)$. This reduction in $\triangle G^{\neq}$may come about either by the stabilization of the transition state with respect to the initial state or by destabilization of the initial state with respect to the transition state. 30

Another approach considers the structure or cohesion of the solvent and how solvent-solvent interactions affect the reacting species.obviously, the over-all effect of a solvent includes both solvation and cohesion, but to date it is extremely diffioult to integrate the two points of view. The cohesive forces of a 1 iquid are electrostatic in nature. At the same time, electrostatic interactions are responsible for non-specific solvation. It is thus very diffcult to consider the two effects separately.32

There are many theories that can give good predictions about the solvent effect on reaction rates.

The Hughes-Ingold Theory is based on the fact that reacting species normally alter their charge distribution during the passage through the transition state of the reaction. Ionic reagents form activated complexes that contain less charge, while neutral molecules form transition states containing some degree of separation of charge. The Hughes-Ingold Theory analyzes the type of charge of a given reaction pathway and the effect of polarity on the charge distribution during the reaction (from initial to transition state).

The alkaline hydrolysis of p-nitrophenyl diphenyl phosphate is a bimolecular reaction between the hydroxide anion and a neutral substrate. According to the Hughes-Ingold Theory, this reaction should be faster when carried out in a polar solvent. In fact, this theory can be used to explain the experimental results observed for solutions containing only water and DMso in the absence of surfactant. This theory really considers the solvent as a continuous medium and does not take into account specific effects. 
Common equations proposed show a linear relationship in terms of functions of the dielectric constant $\varepsilon$, such as $(I / \varepsilon)$, $(\log \varepsilon)$ or $(\varepsilon-1) /(2 \varepsilon+1)$. Such linearity has been observed for reactions in binary solvent systems where the dielectric constant varies with the composition. 37-40

The dielectric constant of the medium was calculated according to Equation VI.

$$
\varepsilon_{\text {medium }}=x_{\mathrm{H}_{2} \mathrm{O}} \cdot \varepsilon_{\mathrm{H}_{2} \mathrm{O}}+\mathrm{x}_{\mathrm{DMSO}} \cdot \varepsilon_{\mathrm{DMSO}}
$$

where $\varepsilon_{\mathrm{H}_{2} \mathrm{O}}=70,5$ and $\varepsilon_{\mathrm{DMSO}}=48,9$ and $\mathrm{x}_{\mathrm{H}_{2} \mathrm{O}}$ and $\mathrm{x}_{\text {DMSO }}$ represent the respective mole fractions of water and dimethyl sulfoxide. 29

Figure 6 illustrates a plot of the $\log \mathrm{k} \psi$ for the reaction versus the function $(\varepsilon-1)(2 \xi+1)$ of the dielectric constant $\varepsilon$ and represents a quantitative correlation of the reaction rate with the dielectric constant. It is really a linear free energy relationship.

An analysis of Figure 6 shows that in the absence of surfactant the plot of $10 \mathrm{~g} k \psi \psi$ versus $f(\varepsilon)$ is essentially a straight line (1ine 1). In the presence of surfactant, however, the plot of $\log \mathrm{k} \psi$ versus $f(\varepsilon)$ gives two straight lines.one of them (1ine 2) describes the behavior for solutions containing 10-50\% DMSO by volume and line 3 for solutions with 50 to $90 \%$ by volume DMSO. One may conclude that the dielectric constant may be used to describe the polarity of the reaction medium. The effect of DMSO on the reaction rate can be described quantitatively in the absence of surfactant ( ${ }_{2} \mathrm{O}-\mathrm{DMSO}$ system) or when the surfactant is present in the form of dispersed monomers $(60-90 \%$ DMSO by volume for the H ${ }_{2}$-DMSO-DEHIES system). In the presence of micelles, the reaction rate is essentially determined by the micelles themselves and the addition of DMSO to the reaction medium is practically masked.

The internal pressure of 1 iquids is given by Equation VII. $41-44$

$$
\begin{aligned}
\mathrm{P}=\Delta \mathrm{H}_{\mathrm{Vap}} / \mathrm{M} \rho & \\
\text { where } I \mathrm{P} & =\text { internal pressure } \\
\Delta \mathrm{H}_{\mathrm{vap}} & =\text { latent heat of vaporization } \\
\mathrm{M} & =\text { molecular weight } \\
\rho & =\text { density of the liquid }
\end{aligned}
$$

The calculated values for the internal pressure of water and dimethyl sulfoxide were 22355,0 atm and 5991,5 atm, respectively.

The internal pressure of the reaction medium was calculated using Equation VIII, and the appropriate mole fractions of $\mathrm{H}_{2} \mathrm{O}$ and DMSO.

$$
I \text { medium }=\mathrm{X}_{\mathrm{H}_{2} \mathrm{O}} \cdot \mathrm{IP} \mathrm{H}_{2} \mathrm{O}+\mathrm{X}_{\text {DMSO }} \cdot I \cdot \mathrm{P}_{\text {DMSO }}
$$




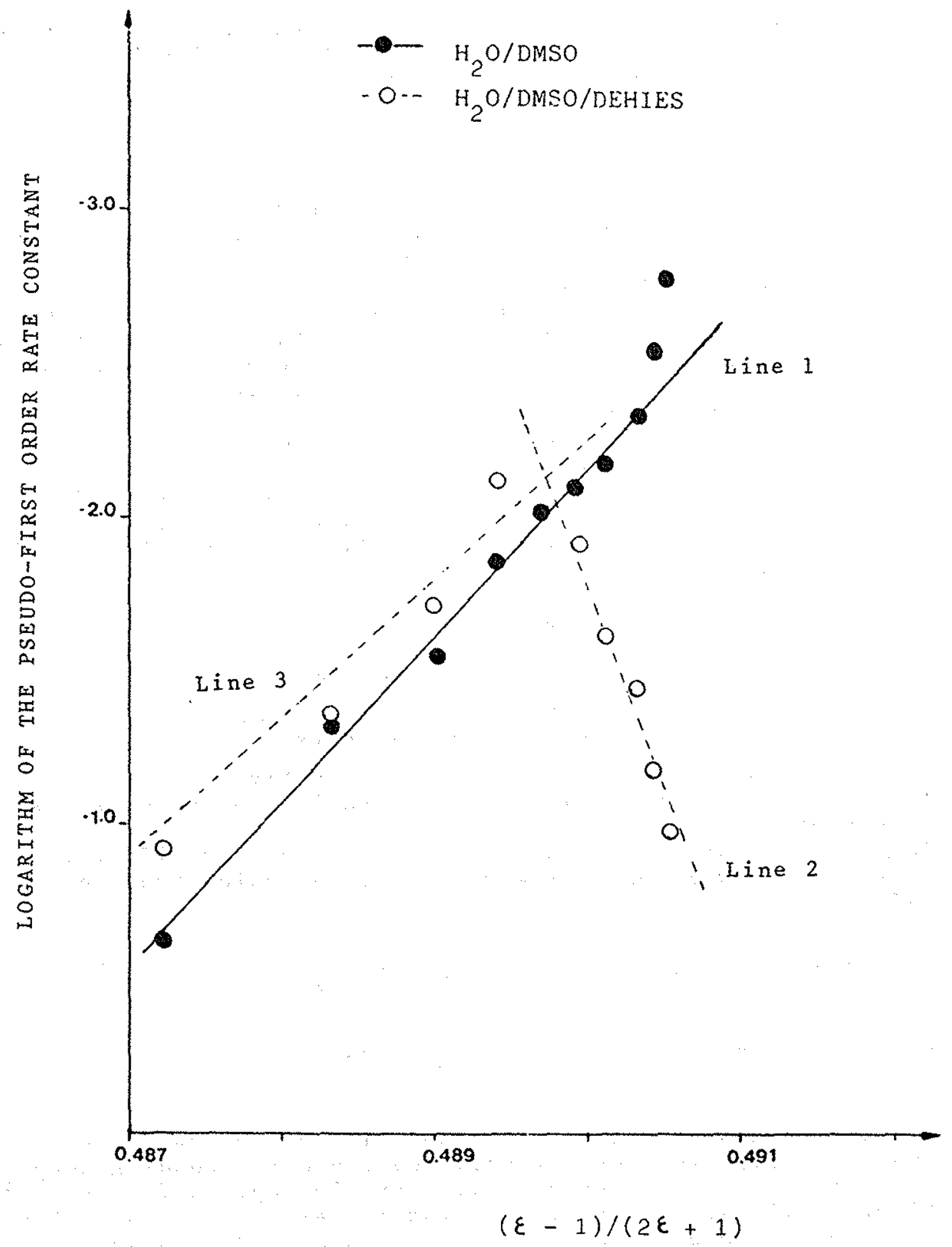

FIGURE 6. PLOT OF THE LOGARITHM OF THE RATE CONSTANT FOR THE HYDROLYSIS OF PNFDF AT 250C IN THE PRESENCE OF $0,010 \mathrm{M} \mathrm{NaOH}$, DMSO AND DEHIES VERSUS A FUNCTION OF THE DIELECTRIC CONSTANT OF THE MEDIUM. 
Figure 7 shows a plot of $10 \mathrm{~g} \mathrm{k} \psi$ versus the internal pressure of the medium for $\mathrm{H}_{2}$ O-DMSO and $\mathrm{H}$ O-DMSO-DEHIES solutions at 25 OC. For the case of water-dimethyl sulfoxide solutions without surfactants the plot is essentially a straight line (line 1). For the $\mathrm{H}_{2}$ O-DMSO-DEHIES system containing $15 \times 10^{-4} \mathrm{M}$ surfactant, there are two straight lines, one describing the behavior in the reaction medium containing 10 to $60 \%$ by volume DMSO ( 1 ine 2) and the other ( 1 ine 3 ) for solutions containing 60 to $90 \%$ DMSO. The influence of the internal pressure of the reaction medium on the reaction $r a t e$ in the absence of surfactant or when it is present in dispersed form ( 60 to $90 \%$ DMSO) indicates that the activated complex formed during hydrolysis of PNFDF in alkaline medium occupies a larger volume than that of the reagents involved in the reaction. In the presence of micelles, the activated complex is in the interior of the micelles and the reaction rate is determined by the micellar medium. The cohesive effect of the solvent medium ( $\mathrm{H}_{2} \mathrm{O}$-DMSO) is essentially masked.

A multi-parameter correlation was also done in order to consider specific solute-solvent interactions. The parameters used were polarity ( $E_{T}$ ) and donor number ( $D N$ ), one representing acidity, the other basicity of the solvent. 36 The realation used is given by Equation IX.

$$
\begin{aligned}
& \log \mathrm{k}_{\psi}=\log \mathrm{k}_{\mathrm{O}}+\mathrm{a} \mathrm{E}_{\mathrm{T}}+\mathrm{b} \mathrm{DN} \\
& \text { where } E_{T}=\text { polarity of the solvent } \\
& D_{N}=\text { donor number of the solvent } \\
& a, b=\text { regression coefficients }
\end{aligned}
$$

The negression coefficients describe the sensitivity of the reaction rate on electrophilic and nucleophilic characteristics of the solvent.

The polarity and donor number of the medium for different concentrations of DMSO present were calculated using Equations $X$ and $X I$.

$$
\begin{aligned}
& E_{T} \text { medium }=x_{H_{2} O} \cdot E_{T H_{2} O}+x_{D M S O} \cdot E_{T \text { DMSO }} \\
& \text { DN medium }=x_{H_{2} O} \cdot D_{H_{2}} O+x_{D M S O} \cdot D_{D M S O}
\end{aligned}
$$

The polarity values used for water and dimetyl sulfoxide were 63,1 and $45,0 \mathrm{cal} / \mathrm{mole}$, respectively and the corresponding donor numbers were 18,0 for water and 29,8 for dimethyl sulfoxide.29,45: Figure 8 illustrates a plot of $\log k+$ as a function of the mole fraction of DMSO for solutions containing $\mathrm{H}_{2} \mathrm{O}-\mathrm{DMSO}$ and $\mathrm{H}_{2}$ O-DMSO-DEHIES at $250 \mathrm{C}$ for the multi-parameter correlation function given by Equation IX. 


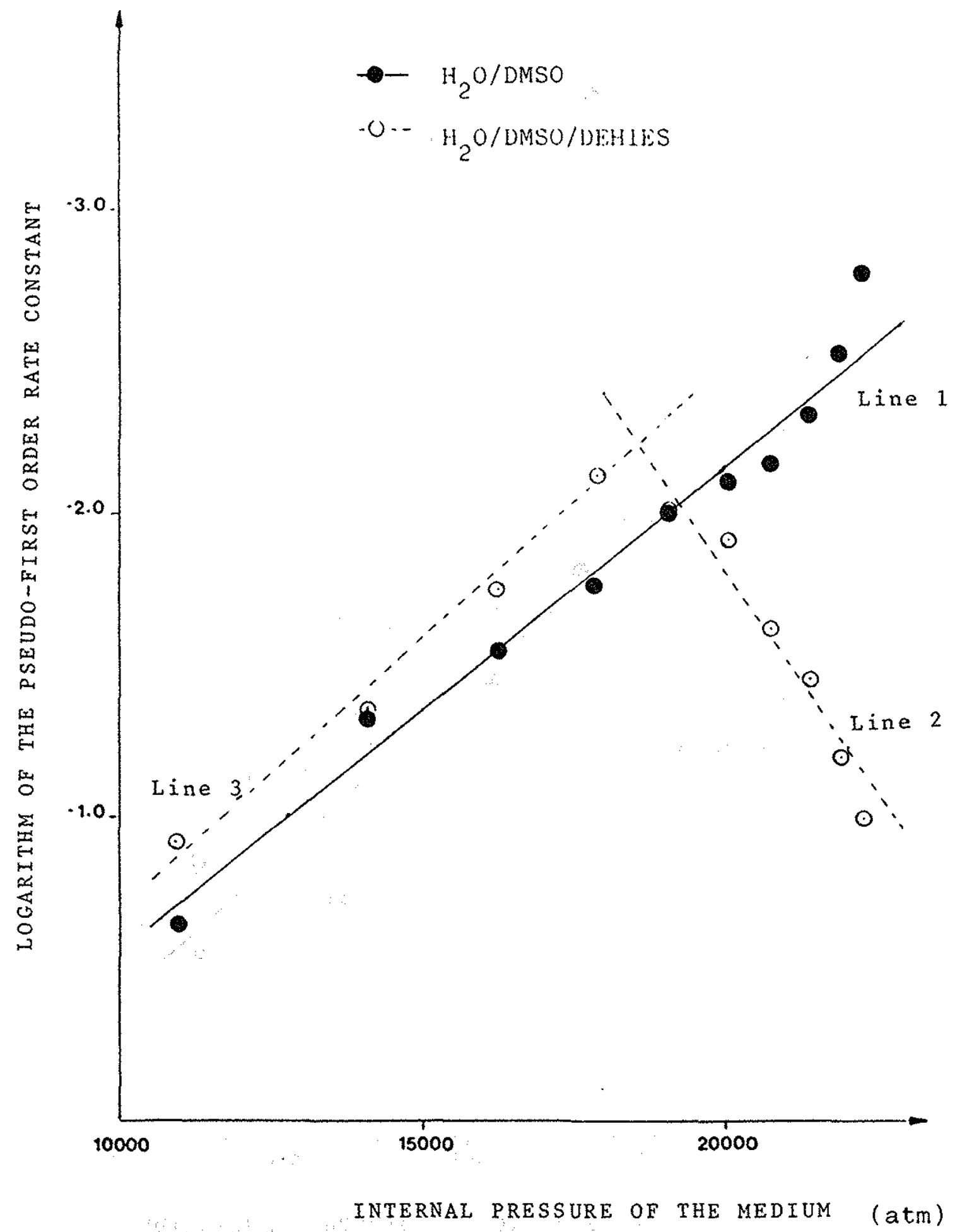

FIGURE 7. PLOT OF THE LOGARITHM OF THE PSEUDO-FIRST ORDER RATE CONSTANT FOR THE HYDROLYSIS OF PNFDE AT $25 \% \mathrm{C}$ IN THE PRESENCE OF $0,010 \mathrm{M} \mathrm{NaOH}$, DEHIES AND DMSO VERSUS THE INTERNAL PRESSURE OF THE MEDIUM. 


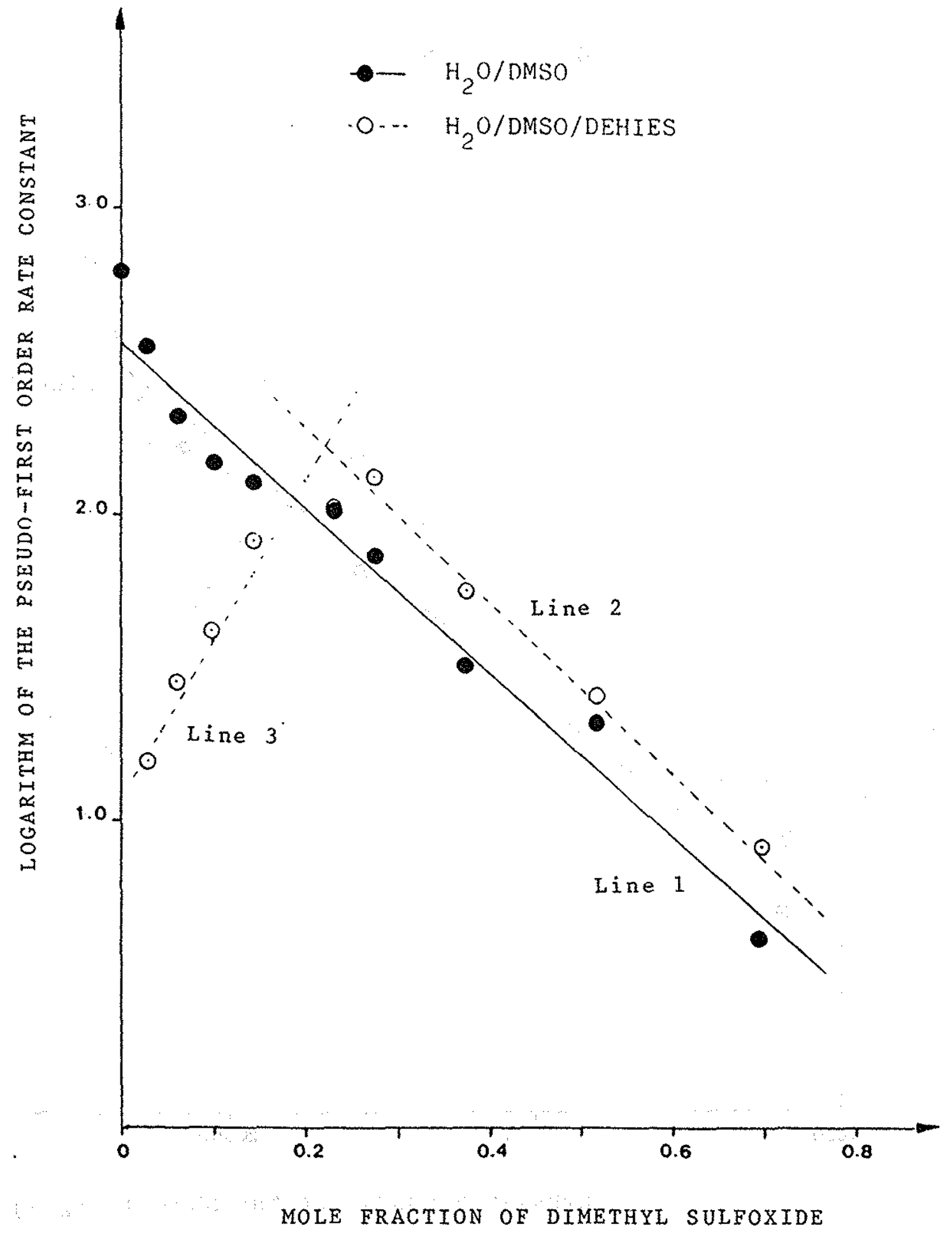

FIGURE 8. PLOT OF THE LOGARITHM OF THE PSEUDO-FIRST ORDER RATE CONSTANT FOR THE HYDROLYSIS OF PNFDF AT $250 \mathrm{C}$ IN THE PRESENCE OF $0,010 \mathrm{M} \mathrm{NaOH}$, DEHIES AND DMSO VERSUS THE MOLE FRACTION OF DMSO FOR A MULTIPARAMETER CORRELATION . 
Again, in the absence of surfactant, the result is a straight line (line 1) with $a=-0,0423$ and $b=0,1647$. In the presence of $15 \times 10^{-4} \mathrm{M}$ DEHIES the behavior of $\log k \psi$ is described by two two straight 1 ines. One of them (1ine 2) describes the behavior of solutions containing $10-50 \%$ by volume DMSO $(a=0,0783$ and $b=-0,2785$ ) and the other one (1ine 3) describes the behavior for solutions containing 60-90\% DMSO $(a=-0,0593$ and $b=0,1172)$. These results indicate that in the absence of surfactant $(a=-0,0423$ and $b=0,1647)$ or when the surfactant is present in dispersed form $(a=-0,593$ and $b=0,1172)$ the reaction medium shows a negative influence of the electrophilic character and a positive influence of the nucelophilic character. In the presence of micelles $(a=0,0783$ and $b=-0,2785)$ the electrophilic contribution becomes positive and the nucleophilic contribution becomes negative.

In summary, we may conclude that all three linear correlation relationships in terms of polarity, internal pressure and multiparameters give similar results and that the formation of the DMSO. $2 \mathrm{H}_{2} \mathrm{O}$ stoichiometric hydrate has a pronounced effect on the formation of micelles and the rate of the micellar catalyzed hydrolysis.

\section{RETRRRNCRS}

1. F. A. Gunther and J. D. Gunther, "Chemistry of Pesticides", Springer Verlag, New York, 1971 .

2. L. S. Goodman and A. Gilman, Eds., "The Pharmacological Basis of Therapeutics", McMillan, New York, 3rd ed., 1966.

3. C. A. Bunton and L. G. Ionescu, J.Amer. Chem. Soc., 95, $2912(1973)$.

4. L. G. Ionescu, BuzZ. N. Mes.Acad. Sei., 24, 65 (1973)

5. L. G. Ionescu and D. A. Martinez, J. Colo. Wyo. Acad. Sci, $7(5), 13(1974)$.

6. C. A. Bunton, S. Diaz, J. M. Hellyer, I. Ihara and I. G. Ionescu, J. Org. Chem., 40, 2313 (1975).

7. F. Nome. E. W. Schwinge1 and I. G. Ionescu, J. Org. Chem., $45,705(1980)$.

8. L. G. Ionescu, D. A. R. Rubio and T.H.M. do Aido, Atual. Fis. Quim. Org., $7,217-229$ (1982).

9. F. Nome. A. Rubira and L. G. Ionescu, J. Phys. Chem., 86, 1181 (1982).

10. L. G. Ionescu and M. J. B. Miguez, Rev, Chim. Industr., $52(609), 23(1983)$.

11. L. G. Ionescu and F. Nome, in "Surfactants in Solution", K, L. Mittal and B. Lindman, Eds., Plenum Press, New York, 1984, Vo1. 2, pp. 1107-1120.

12. L. G. Ionescu and M. J. B. Miguez, Atual. Fis. Quim, Org., 2, 89-102 (1984).

13. L. G. Ionescu, Quim. Nova, 8(z), 191 (1985).

14. L.G. Ionescu, D. A. R. Rubio and L. S. Romanesco, in "Trabalhos Técnicos 40 Seminário Brasileiro de Catálise", Instituto Brasileiro do Petróleo, Rio de Janeiro, Brasil, 1987 , pp. 727-737. 
15. L. G. Ionescu, T.H. M do Aido and B. J. Kid., Bol. Soc. Chil. Quim., 35, 105-111 (1990).

16. A. M. Roos and J. Toet, Rec. Trav. Chim., 77, 946 (1958).

17. A. S. Kirby and M. Jounas, J. Chem. Soc., B, 1165 (1970).

18. C. A. Bunton, L. Robinson and L. Sepulveda, J. Amer. Chem. Soc., 92, 4813 (1969).

19. F, M. Menger, L. H. Gan E. Johnson and D. H. Durst, J.Amer. Chem. Soc., 209, 2802 (1987).

20. L. G. Ionescu, T. Tokuhiro and B, J. Czerniawski, BuZZ. Chem. Soc. Japan, 52, 922-924 (1979).

21. L. G. Ionescu and D. S. Fung, Buzl. Chem. Soc. Japan, 54, 2503-2505 (1981).

22. L. G. Ionescu, L. S. Romanesco and F. Nome, in "Surfactants in Solution", K. L. Mittal and B. Lindman, Eds., Plenum Press, New York, 1984, pp. 789-803.

23. J. M. G. Cowie and P. M. Toporowski, Canad. J. Chem.,39, 2240 (1961).

24. L. G. Ionescu, T. Tokuhiro, B. J. Czerniawski and E. S. Smith, in "Solution Chemistry of Surfactants", K. L. Mittal, Ed., P1enum Press, New York, 1979, Vo1. I, pp. 487-496.

25. T. Tokuhiro, D. S. Fung and L. G. Ionescu, J. Chem. Soc. Earaday Trans. II, 75, 975-984 (1979).

26. T. Tokuhiro and L. G. Ionescu, in "Solution Chemistry of Surfactants", K. L. Mitta1, Ed., Flenum Press, New York, 1979, Vol. I, pp: 497-506.

27. L, G. Ionescu and L. S. Romanesco, Atual. Fis. Quim. Org., $3,109-122(1985)$.

28. L. L. Schaleger and F. A. Long, Adv. Phys. Org. Chem.gi?(2), $1-33(1990)$.

29. A. Finniels and P. N. Geneste, J. Chim. Phys,,76, 521 (1979).

30. O. Popovich and R. P. T. Tomkins, "Nonaqueous Solution Chemistry", John Wiley and Sons, New York, 1981.

31. C. Agami, Buzz. Soc. Chim. France, 5, 1021-1039 (1965).

32. A. J. Parker, Chem. Rev., 69, 1-32 (1969).

33. L. G. Ionescu, Contrib. Cient. Tecnol. Santiago(chite), NS, 35-39 (1985).

34. K. Burger, "Solvation, Ionic and Complex Formation Reactions in Non-Aqueous Solvents", Elsevier Scientific Co., Amsterdam, 1983, pp. 217-243.

35. B. G. Cox and W. E. Waghorne, Chem. Soc. Rev., 9(3), 381-411 $(1980)$.

36. L. Albuquerque and $\mathrm{R}$. Gonçalves, "Cinética Quimica", Editora Escolar, Lisboa, Portugal, 1986.

37. E. Buncel and H. Wilson, Adv. Phys. Org. Chem., 24, 133-202 (1977). 
38. M. R. J. Dack, The Influence of Solvent on Chemical Reactivity, in "Technique of Organic Chemistry", A. Weissberger, Ed., Interscience Publishers, New York, 1976, Vol. VIII.

39. J. Hine, "Physical Organic Chemistry", McGraw Hill Book Company, New York, 1962, 2nd edition.

40. E. S. Amis and J. F. Hinton, "Solvent Effects on Chemical Phenomena", Academic Press, New York, 1973, Vo1. 1.

41. J. R. Partington, "An Advanced Treatise on Physical Chemistry", Vol. 2, The Properties of Liquids, Longman's, Green and Company, London, 1951.

42. R. C. Reid and J.M. Prausnitz, "The Properties of Gases and Liquids", McGraw Hil1, New York, 1972, 3xd edition.

43. R. H. Perry and C. H. Clinton, Eds., "Chemical Engineer's Handbook", McGraw Hill Kogakusha, Tokyo, 1973, 3rd edition.

44. R. C. Weast, Editor, "CRC Handbook of Chemistry and physics", CRC Press, Boca Raton, Florida, USA, 1981, 61st edition.

45. V. Gutman, "The Donor-Acceptor Approach to Molecular Interactions", Plenum Press, New York, 1978. 